Article

\title{
Development and Field Tests of a Deep-Sea Laser-Induced Breakdown Spectroscopy (LIBS) System for Solid Sample Analysis in Seawater
}

\author{
Chunhao Liu, Jinjia Guo *, Ye Tian, Chao Zhang, Kai Cheng, Wangquan Ye and Ronger Zheng \\ College of Information Science \& Engineering, Ocean University of China, Qingdao 266100, China; \\ liuchunhao@stu.ouc.edu.cn (C.L.); ytian@ouc.edu.cn (Y.T.); zhangc_ouc@163.com (C.Z.); \\ chengkai@ouc.edu.cn (K.C.); yewangquan@ouc.edu.cn (W.Y.); rzheng@ouc.edu.cn (R.Z.) \\ * Correspondence: opticsc@ouc.edu.cn; Tel.: +86-532-6678-1211
}

Received: 27 November 2020; Accepted: 18 December 2020; Published: 21 December 2020

\begin{abstract}
In recent years, the investigation and exploitation of hydrothermal region and polymetallic mineral areas has become a hot topic. The emergence of underwater vehicle platforms has made it possible for new chemical sensors to be applied in marine in-situ detection. Laser-induced breakdown spectroscopy (LIBS), with its advantages of rapid real-time analysis, sampling without pretreatment, simultaneous multi-element detection and stand-off detection, has great potential in marine applications. In this paper, a newly more compact and lighter underwater LIBS system based on the LIBSea system named LIBSea II was developed and tested both in the laboratory and sea trials. The system consists of a Nd:YAG single-pulse laser at $1064 \mathrm{~nm}$, a fiber spectrometer, optical layout, a power supply module and an internal environment sensor. The system is encapsulated in a pressure vessel $(\Phi 190 \mathrm{~mm} \times \mathrm{L} 588 \mathrm{~mm}$ ) with an optical window on the end cap. Experimental parameters of the system including laser energy and delay time were firstly optimized in the laboratory. Then, field test of the system in nearshore was performed with various samples, including pure metal and alloy samples as well as a manganese nodule sample from deep sea, to verify the detection performance of the LIBSea II system. In 2019, the system was deployed on a remotely operated vehicle (ROV) of Haima for deep sea trial, and atomic lines of $\mathrm{K}, \mathrm{Na}, \mathrm{Ca}$ and strong molecular bands of $\mathrm{CaOH}$ from a carbonate rock sample were obtained for the first time at depths of $1400 \mathrm{~m}$. These results show that the LIBSea II system has great potential to be used in deep-sea geological exploration.
\end{abstract}

Keywords: LIBS instrumentation; underwater solid analysis; field test; in-situ detection; deep-sea

\section{Introduction}

Deep-sea hydrothermal area and polymetallic mineral areas are widely distributed all over the world. Due to their abundance of metal resources, these areas have become the focus of marine research in recent years. Traditional analytical methods are diversified, and it is usually required to analyze the samples after obtaining them from the deep sea. The number of samples that can be retrieved limits the range and spatial resolution of the information obtained, and the information is not immediately available for feedback since the analysis is typically performed in a laboratory [1]. There are not many analytical techniques available for the in-situ exploration of underwater sites, and therefore the development of in-situ instruments is highly demanded, in particular those based on optical technologies. Oceanic in-situ sensors based on spectroscopic technology have many advantages, such as simultaneous detection of multiple components, non-contact, high speed in analysis, wide adaptability, strong flexibility, and are becoming one of the hot topics in marine research. Recently, with the rapid development of underwater vehicle platforms, it will be convenient that kinds of in-situ optical sensors are used for ocean observation and exploration. 
As a newly developed spectroscopic technology, laser-induced breakdown spectroscopy (LIBS) has been widely applied in various fields [2-6], especially the ChemCam system applied in Mars exploration has attracted the worldwide attention [7-9]. However, due to the high density, compression resistance and high heat conductivity of water [10], compared with the successful applications in air environment, it is still a big challenge to apply LIBS technology to deep-sea research. Up to now, most of the underwater LIBS studies are carried out in the laboratory, including the laser irradiation method [11-13], spectrum detection mode [14] and underwater high-pressure effect [15-18] and data processing of underwater LIBS spectrum $[19,20]$. Only a few scientific research institutions have carried out the in-situ oceanic applications of LIBS technology.

The University of Malaga in Spain has reported two sets of equipment that can be used for archaeological investigations in shallow sea [21,22]. Both of them consist of a ship-borne part and a probe part, which are connected by an optical fiber for transmission of the ablation laser and the LIBS signal. Compared with the first-generation equipment, the second-generation equipment named AQUALAS 2.0 reduces the weight of the ship-borne part (from $300 \mathrm{~kg}$ to $150 \mathrm{~kg}$ ) and with a longer optical fiber. The use of multi-pulse laser detection in the second-generation system has greatly improved the performance of the instrument. Recently, the University of Tokyo and Ocean University of China have applied LIBS technology to in-situ detection in deep sea. The University of Tokyo developed the $3000 \mathrm{~m}$ rated I-SEA system and ChemiCam system successively $[1,23,24]$. They all adopt a segmented design which is divided into two parts: the main housing and the fiber probe head. The two parts are connected by a fiber optic cable. When working, the liquid detection was carried out in the main housing, while the solid detection was completed by the optical fiber probe with the help of the remotely operated vehicle (ROV) manipulator. The I-SEA system has performed multi-elements analysis in seawater as well as phosphatised carbonate samples at a depth of $200 \mathrm{~m}[23,24]$. Later, the ChemiCam system has measured the hydrothermal fluid and sediment successfully at the Iheya North field in the Okinawa trough at a depth over $1000 \mathrm{~m}$ [24], and the in-situ quantitative analysis of deep-sea minerals in the hydrothermal area was carried out for the first time [25]. Ocean University of China developed a compact $4000 \mathrm{~m}$ rated deep-sea LIBS system (LIBSea) by using the integrated design in 2015. The system has performed the detection of hydrothermal fluid in Manus area and the measurement of seawater profile with the diving of Faxian ROV [26,27]. The major metallic elements, $\mathrm{Na}, \mathrm{Ca}, \mathrm{K}, \mathrm{Mg}$, as well as $\mathrm{Li}$, were clearly detectable in the spectra obtained at sea floor in the hydrothermal area, and the elemental profiles of LIBS signals of $\mathrm{K}$ and Ca were also obtained during the sea trials.

In order to realize the underwater LIBS system that can be easily gripped by the ROV manipulator, a more compact, lighter and lower power consumption deep-sea LIBS system (LIBSea II) is developed on the basis of the LIBSea system. When working, the system can be directly gripped by the ROV manipulators with the functioning of T-handles for the detection of submerged solid targets. In this paper, the configurations and specifications of LIBSea II system will be first introduced in detail. Then the optimization of system parameters in the laboratory together with the comparative tests of metal targets in the shallow sea will be shown. Field-test results including the quantitative analysis of alloy targets and manganese nodule from deep sea in shallow sea and the LIBSea II system with carbonate rock sample deployed on remotely operated vehicles for deep sea detection will also be presented.

\section{Experimental Setup}

Figure $1 \mathrm{a}$ is the newly developed underwater system named LIBSea II. It is packed into one cylindrical pressure housing made of 7075 aluminum alloy which was treated by surface oxidation blackening to retard corrosion. The size of the system is $588 \mathrm{~mm}$ in length and $190 \mathrm{~mm}$ in diameter capable of withstanding $50 \mathrm{MPa}$ with a $25 \%$ safety margin. The total weight of the LIBSea II system is $28 \mathrm{~kg}$ in air, which is much lighter than that of the LIBSea system (56 kg in air) [26]. Because the system weighs only $12 \mathrm{~kg}$ in water, it can be easily hold by a manipulator of ROV. The system is 
usually deployed with ROVs for deep-sea measurements. The ROV is a powerful underwater vehicle for subsea exploration, attached to a photoelectric composite umbilical cable to the deck over which the communication signal and the electric power are transmitted. With the powerful communication capabilities of the ROV based on its umbilical cable, the entire system could operate in interactive mode through high-rate interfaces (Gigabit Ethernet interface). Interactive mode enables operators on the deck to communicate with underwater instruments through remote desktop and the returned spectrum data can be displayed on the computer screen in real time and will help us analyze the quality of the data in time. It can be seen in Figure $1 \mathrm{a}$ that there are three connecting ports on the end of cylindrical housing which can be adapted to most ROVs in China The first port is used to connect the low-rate interfaces on ROVs for automatic mode or laboratory tests, and another two for connecting the high-rate interfaces on different ROVs to display data in real time at the deck terminal or the internal communication between other systems on requiring. During the experiment of LIBSea II in deep sea, the power supply of the system is provided by the ROV the power and ethernet cables. A power converter in the pressure housing is used to realize the conversion of DC to DC. The output voltages are $24 \mathrm{~V}$ DC and $5 \mathrm{~V}$ DC that were supplied to the Nd:YAG pulsed laser and the embedded computer, respectively. The power supply for the optical spectrometer is provided by the embedded computer USB interface. When the ROV starts to supply power to the system, the embedded computer in the pressure housing will start automatically, and the operator controls the LIBSea II system through the remote desktop. And an integrated USB environment sensor is used to monitor the temperature, humidity and pressure to monitor the internal environment of the system and ensure the safety during the experiments in deep sea. There is a specially designed optical probe on the front end of the housing for submerged solids detection.

(a)

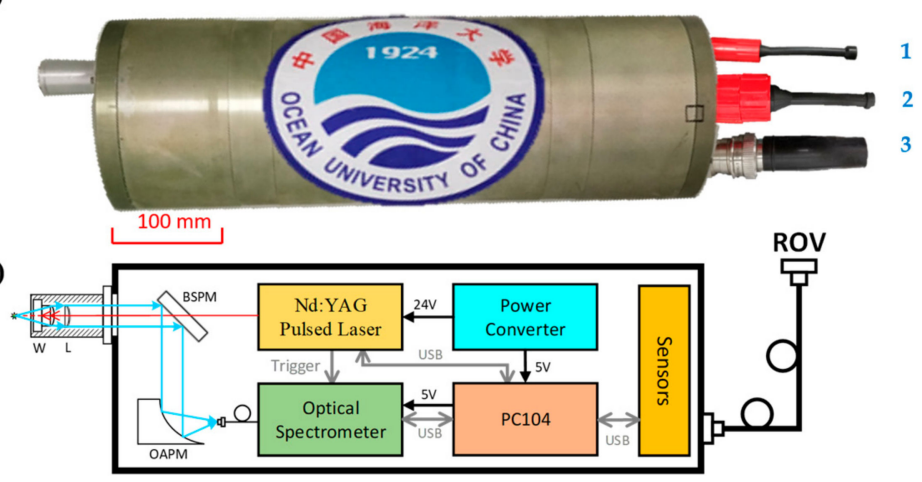

Figure 1. (a) The photo of the newly developed underwater LIBS device (LIBSea II). (b) Schematic of the LIBSea II system showing the optical layout, pulsed laser, optical spectrometer, embedded computer, power converter and environment sensor.

To make the system compact in size and light in weight, the core instruments were carefully selected and modified to meet the requirements of underwater working. The LIBSea II system is shown schematically in Figure 1b. The cross-sections of the cylindrical pressure housings are plotted in solid line giving a reference space measure for the whole package of the spectral systems. A Q-switched neodymium-doped yttrium aluminum garnet (Nd:YAG) laser (M-NANO, Montfort, Götzis, Austria) operating in a fundamental frequency with a pulse duration of $10 \mathrm{~ns}$ was used as the excitation source giving a maximum pulse energy of $40 \mathrm{~mJ}$ at the repetition rate of $2-25 \mathrm{~Hz}$. The laser can be operated from 0 to 50 degrees Celsius for adapting to the lower temperature of deep-sea environment. Also, the core instrument can be cooled by thermal conduction through the walls of the high-pressure housing. Although the laser wavelength of $1064 \mathrm{~nm}$ is absorbed seriously in water, it can be used as the excitation source for a better detection capability [28]. The whole laser package was modified into a compact size of $258 \mathrm{~mm}(\mathrm{~L}) \times 78 \mathrm{~mm}(\mathrm{~W}) \times 64 \mathrm{~mm}(\mathrm{H})$ for underwater operation. To obtain a 
high-quality LIBS signal, special attentions are paid on the design of the focusing lens of the LIBSea II system. Single plano-convex lens is not suitable to be used as the focusing lens in underwater LIBS measurement, because of its large spherical aberration, which can lead to a low repeatability of the underwater LIBS signals [29]. There are many ways to reduce the spherical aberration, such as using the doublet lens or the combination of two single lens. As shown in our previous work [29,30], the application of a doublet lens together with a large focusing angle can greatly improve the stability of the plasma and lead to high-quality LIBS signals. However, in the practical case, there is a certain safety risk because the doublet lens may be damaged by the high-energy laser pulse. Therefore, in this work, the combination of double plano-convex lenses has been used in LIBSea II system. We have verified in the laboratory that the spherical aberration can be clearly reduced with this focusing arrangement and the quality of LIBS signals can be improved [31]. The optical probe consists of a specially designed lens (W, shown in Figure $1 \mathrm{~b}$, is a specially designed fused silica plano-convex lens with a $11.82 \mathrm{~mm}$ curvature radius and $16.36 \mathrm{~mm}$ thickness) and a fused silica plano-convex lens (L, shown in Figure 1b) with $50.2 \mathrm{~mm}$ in focal length. At the same time, the specially designed lens is also served as a pressure-resistant optical window. It also has to pass the hydrostatic pressure test of 62.5 MPa for deep-sea experiments. The plasma emission of seawater is induced by the tightly focused laser beam at a $7.8 \mathrm{~mm}$ distance away which can avoid the strong laser absorption in water and ensure more lights throughput of plasma signal from the optical window. The emission is then collected by the same optics. After being reflected by a back side polished mirror (BSPM, Reflectance $>95 \%$ at 400-800 $\mathrm{nm}$ and Transmission $>90 \%$ at $1064 \mathrm{~nm}$ ) and an off-axis parabolic mirror (OAPM, focusing a collimated beam without chromatic aberrations), the collected LIBS signal is then coupled into a compact optical spectrometer (AvaSpec-Mini2048, Avantes, Apeldoorn, Netherlands), which offers a wavelength coverage of $260-800 \mathrm{~nm}$ and a spectral resolution of $0.63 \mathrm{~nm}$ with a 2048 pixels CCD. The spectrometer was triggered by the customized pulsed laser. In order to eliminate the original delay time $(1.28 \mu \mathrm{s})$ of the optical spectrometer, the laser can set appropriate Q-switch trigger signal to offset the delay time. The detailed specifications of LIBSea II system are listed in Table 1.

Table 1. General Specifications of the LIBSea II System.

\begin{tabular}{|c|c|c|}
\hline Module & Apparatus & Specifications \\
\hline Mechanics & $\begin{array}{l}\text { Pressure } \\
\text { vessel }\end{array}$ & $\begin{array}{l}7075 \text { Aluminum alloy, anodized surface } \\
588 \times 190 / \text { length }(\mathrm{mm}) \times \text { diameter }(\mathrm{mm}) \\
28 \mathrm{~kg}(12 \mathrm{~kg}) / \text { weight in air }(\text { water }) \\
50 \mathrm{MPa} / \text { pressure proof } \\
62.5 \mathrm{MPa} \text { /hydrostatic pressure }\end{array}$ \\
\hline \multirow{4}{*}{ Optics } & $\begin{array}{c}\text { Laser: } \\
\text { (Montfort, } \\
\text { M-NANO) }\end{array}$ & $\begin{array}{l}1064 \mathrm{~nm}, \mathrm{Nd}: Y A G \\
\leq 40 \mathrm{~mJ} / \text { pulse energy } \\
2-25 \mathrm{~Hz} / \text { adjustable repetition rate } \\
10 \mathrm{~ns} / \text { pulse width } \\
258 \times 78 \times 64 / \text { dimension }\left(\mathrm{mm}^{3}\right)\end{array}$ \\
\hline & $\begin{array}{c}\text { Spectrometer: } \\
\text { (Avantes, } \\
\text { AvaSpec-Mini2048) }\end{array}$ & $\begin{array}{l}260-800 \mathrm{~nm} / \text { wavelength range } \\
0.63 \mathrm{~nm} / \text { spectral resolution } \\
1280 \mathrm{~ns} / \text { minimum detection delay } \\
1 \mathrm{~ms} / \text { minimum integration time } \\
120 \times 90 \times 35 / \text { dimension }\left(\mathrm{mm}^{3}\right)\end{array}$ \\
\hline & $\begin{array}{l}\text { Optical } \\
\text { window }\end{array}$ & $\begin{array}{l}\text { Fused silica } \\
19 \times 16.35 / \text { diameter }(\mathrm{mm}) \times \text { thickness }(\mathrm{mm}) \\
15 \mathrm{~mm} / \text { focal length } \\
50 \mathrm{MPa} / \text { pressure proof } \\
62.5 \mathrm{MPa} \text { /hydrostatic pressure }\end{array}$ \\
\hline & Layout & Confocal collection \\
\hline \multirow{4}{*}{ Electronics } & Power supply & $110 \mathrm{~V}$ AC/48 V DC from ROV \\
\hline & Delay generator & $800-4400$ ns/Q-Switch out from laser \\
\hline & Microcomputer & PC 104/Advantech PCM-3363 \\
\hline & Communication & $\begin{array}{l}\text { Ethernet/USB/RS232/RS485 } \\
\text { Remote desktop connection }\end{array}$ \\
\hline
\end{tabular}




\section{Results and Discussion}

\subsection{Optimization of System Parameters in Laboratory}

Experimental parameters of the system including delay time and laser energy were first optimized with a submerged copper target in laboratory. One important parameter is the detection delay time, which is used to avoid the interference of the continuum emission from the early stage plasma after the laser pulse. Figure 2a shows the peak intensity of LIBS signal at Cu I $510 \mathrm{~nm}$ with different delay time. It can be seen that the signal intensity tends to increase first and then decrease. Due to the strong bremsstrahlung in the early stage of plasma evolution, the continuous background of the spectral line is high. As time evolves, the plasma in water cools down rapidly and the continuous background decreases significantly. The highest peak intensity is found at a delay time of $400 \mathrm{~ns}$. After this time the signal gradually weakens and disappears at $1400 \mathrm{~ns}$. In addition, the optimization of laser energy is also very important for obtaining high-quality LIBS signal, especially for the underwater measurements. With low laser energy, a 100\% breakdown probability cannot be achieved, while with high laser energy, the plasma in water suffers a strong shielding effect that degrades the LIBS signals. Figure $2 \mathrm{~b}$ shows the spectral intensity of LIBS signal at $\mathrm{Cu}$ I $510 \mathrm{~nm}$ as a function of laser energy. The spectra were recorded at a delay time of $400 \mathrm{~ns}$ and with an average of 50 laser shots. It can be seen that as the laser energy increases, the signal intensity rises from 1 to $6 \mathrm{~mJ}$. This is because when the energy is low, the laser fluence cannot reach the breakdown threshold to achieve an efficient ablation on the target surface. As the laser energy increases, the ablation mass of the target will be increased, so that the LIBS signal is enhanced. The signal intensity reaches the maximum value at $6 \mathrm{~mJ}$. And then the signal began to show a clearly decrease trend with the increased energy. This is mainly because the continual increase in energy will lead to the probability of breakdown in the water medium instead of on the target surface. A strong plasma shielding phenomenon occurs in this case which leads to a clearly decrease of the LIBS signal. Based on these results, an optimal laser energy of $6 \mathrm{~mJ}$ and delay time of 400 ns were used for the following field tests.
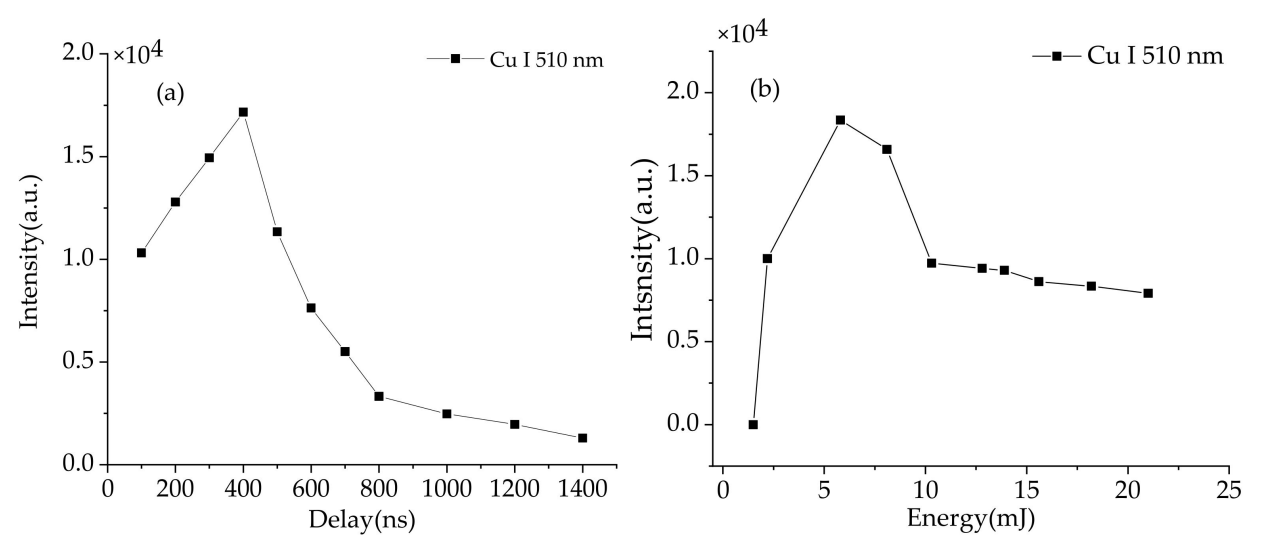

Figure 2. (a) Spectral intensity of Cu I $510 \mathrm{~nm}$ under different delay time. (b) Spectral intensity of Cu I $510 \mathrm{~nm}$ under different laser energy.

\subsection{Shallow Sea Experiments}

In order to evaluate the performance of LIBSea II for submerged solid detection, a series of shallow-sea experiments were performed in nearshore of the Jiaozhou Bay. The system was running during 9:00 a.m. to 18:14 p.m. on 23 November 2018. The air temperature was reported from $8{ }^{\circ} \mathrm{C}$ to $17^{\circ} \mathrm{C}$ and the experiment positions were exposed to a level 3 southwest wind. The measurement location is $36^{\circ} 04^{\prime} 26^{\prime \prime} \mathrm{N}, 120^{\circ} 18^{\prime} 43^{\prime \prime} \mathrm{E}$ and the map of the location was shown in Figure 3 . The rack-mounted system was deployed at a depth of $5 \mathrm{~m}$ on the seafloor for the shallow-sea test. The used samples are pure metal targets of $\mathrm{Zn}, \mathrm{Cu}, \mathrm{Al}, \mathrm{Fe}$, a series of $\mathrm{Zn}-\mathrm{Cu}$ alloy targets with different $\mathrm{Zn} / \mathrm{Cu}$ mass ratios 
and manganese nodules sample from deep sea. The spectra were recorded with the same experimental parameters optimized in the laboratory (i.e., $6 \mathrm{~mJ}$ laser energy, $400 \mathrm{~ns}$ delay time).

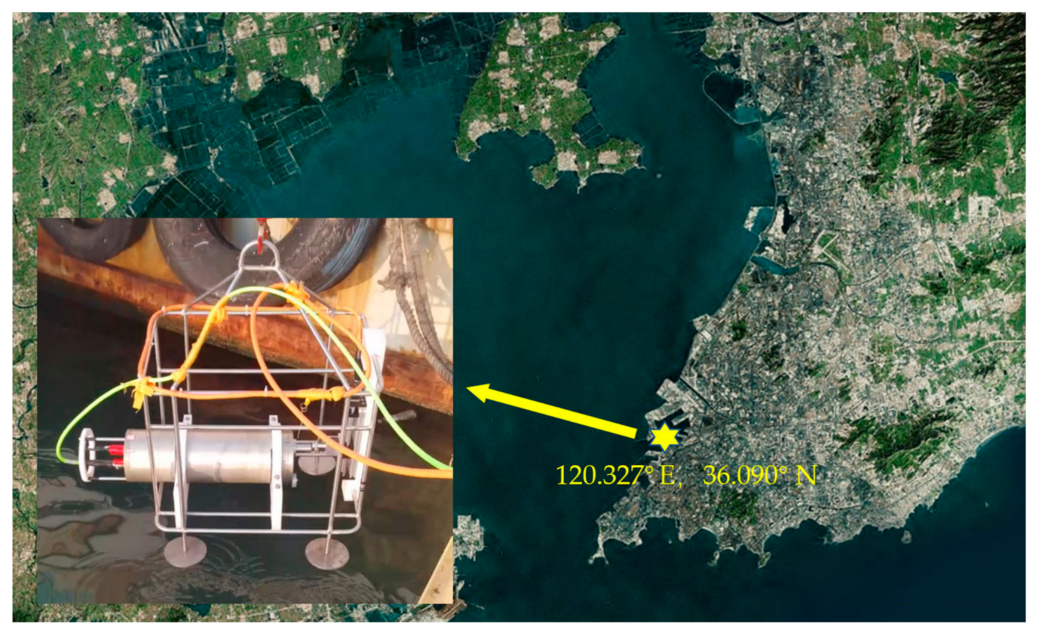

Figure 3. Map showing the location of nearshore underwater measurement in the Jiaozhou Bay. The system is placed on the mounting frame and lifted underwater by the shipboard motor.

Figure $4 \mathrm{a}-\mathrm{d}$ show the spectra of pure metal targets of $\mathrm{Zn}, \mathrm{Cu}, \mathrm{Al}$, and Fe measured by LIBSea II system in shallow sea (black line) as well as in laboratory (red line).
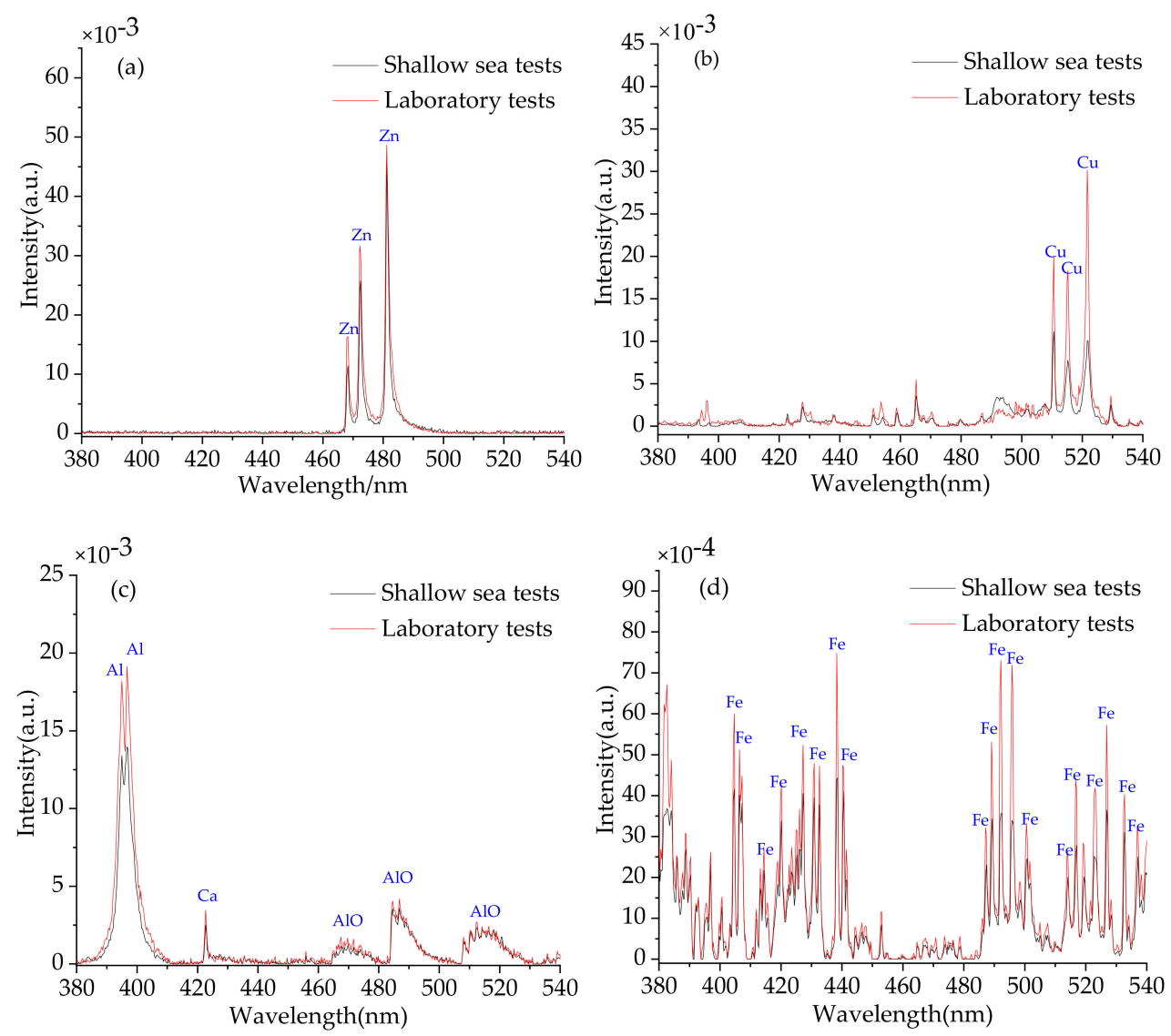

Figure 4. Spectra of pure metal targets of (a) Zn, (b) Cu, (c) Al, (d) Fe measured in shallow sea (black line) and in laboratory (red line) for comparison. 
The spectra were preprocessed by background subtraction and normalization for comparison purpose due to the different water environment. The background was subtracted using symmetrically reweighted penalized least squares method [32], and each spectrum was normalized by the total intensity of the whole spectrum $[1,13]$. According to the NIST atomic spectra database, the characteristic lines of the corresponding elements are identified in the figure. We can see that characteristic lines of $\mathrm{Zn}, \mathrm{Cu}, \mathrm{Al}$, and $\mathrm{Fe}$ are all clearly visible in the spectra. Among them, we can find the characteristic lines of Zn I 468/472/481 nm (3d ${ }^{10} 4 \mathrm{~s} 5 \mathrm{~s}^{3} \mathrm{~S}_{1}-3 \mathrm{~d}^{10} 4 \mathrm{~s} 4 \mathrm{p}{ }^{3} \mathrm{P}_{0}^{0}{ }_{0}, 3 \mathrm{~d}^{10} 4 \mathrm{~s} 5 \mathrm{~s}{ }^{3} \mathrm{~S}_{1}-3 \mathrm{~d}^{10} 4 \mathrm{~s} 4 \mathrm{p}{ }^{3} \mathrm{P}^{0}{ }_{1}, 3 \mathrm{~d}^{10} 4 \mathrm{~s} 5 \mathrm{~s}$ $\left.{ }^{3} \mathrm{~S}_{1}-3 \mathrm{~d}^{10} 4 \mathrm{~s} 4 \mathrm{p}{ }^{3} \mathrm{P}^{0}{ }_{2}\right)$, Cu I 510/515/521 nm (3d ${ }^{10} 4 \mathrm{p}^{2} \mathrm{P}^{0} 3 / 2-3 \mathrm{~d}^{9} 4 \mathrm{~s}^{2}{ }^{2} \mathrm{D}_{5 / 2}, 3 \mathrm{~d}^{10} 4 \mathrm{~d}^{2} \mathrm{D}_{3 / 2}-3 \mathrm{~d}^{10} 4 \mathrm{p}^{2} \mathrm{P}^{0}{ }_{1 / 2}$, $\left.3 \mathrm{~d}^{10} 4 \mathrm{~d}{ }^{2} \mathrm{D}_{5 / 2}-3 \mathrm{~d}^{10} 4 \mathrm{p}^{2} \mathrm{P}^{0}{ }_{3 / 2}\right)$, Al I 394/396 nm $\left(3 \mathrm{~s}^{2} 4 \mathrm{~s}^{2} \mathrm{~S}_{1 / 2}-3 \mathrm{~s}^{2} 3 \mathrm{p}{ }^{2} \mathrm{P}_{1 / 2}^{0}, 3 \mathrm{~s}^{2} 4 \mathrm{~s}^{2} \mathrm{~S}_{1 / 2}-3 \mathrm{~s}^{2} 3 \mathrm{p} 2 \mathrm{P}^{0}{ }_{3 / 2}\right)$, and there are so many Fe lines that were not listed one by one. We can also find strong AlO molecular band $\left(\mathrm{B}^{2} \Sigma^{+}-\mathrm{X}^{2} \Sigma^{+}\right)$in the wavelength range from 460 to $530 \mathrm{~nm}$ as shown in Figure $4 \mathrm{c}$. The generation of large number of oxygen atoms in plasma due to the effective dissociation of water molecules and the high oxidation rate of the $\mathrm{Al}$ target material result in the formation of $\mathrm{AlO}$ species [33]. By comparing the spectra measured in shallow sea and in laboratory, we can see the difference of the peak intensity on the observed characteristic lines of $\mathrm{Zn}, \mathrm{Cu}, \mathrm{Al}$, and $\mathrm{Fe}$. The difference on the peak intensity of the characteristic lines between the shallow-sea test and laboratory test may be due to the slight change on the lens-to-sample distance (LTSD). Another reason is that for the field test, the LIBS signal may be also influenced by the variation of oceanic parameters such as the pressure [17], temperature [34] and salinity [35]. It can be seen from the results of the comparison that there is almost no difference in other aspects of the characteristic lines (such as the width and wavelength positions of the characteristic peak) except for the intensity of the characteristic peak. This indicates the robustness performance of the LIBSea II system when working in the field shallow-sea environment.

Furthermore, the nearshore detections of submerged mineral samples were performed. The measurements were made using $6 \mathrm{~mJ}$ single pulse energy, $400 \mathrm{~ns}$ observation gate delay, and $1 \mathrm{~ms}$ gate width, which were consistent with those of metal targets. Figure 5 shows the typical spectrum of a manganese nodule sample from deep sea after background subtraction processing, the characteristic lines of major metallic elements of $\mathrm{Fe}$ and $\mathrm{Mn}$ can be observed clearly. For the wavelengths overlap of $\mathrm{Al}$ at 394 and $396 \mathrm{~nm}$ with strong emissions of $\mathrm{Ca}$ (II) and Fe, they can't be distinguished due to the limited resolution of the spectrometer.

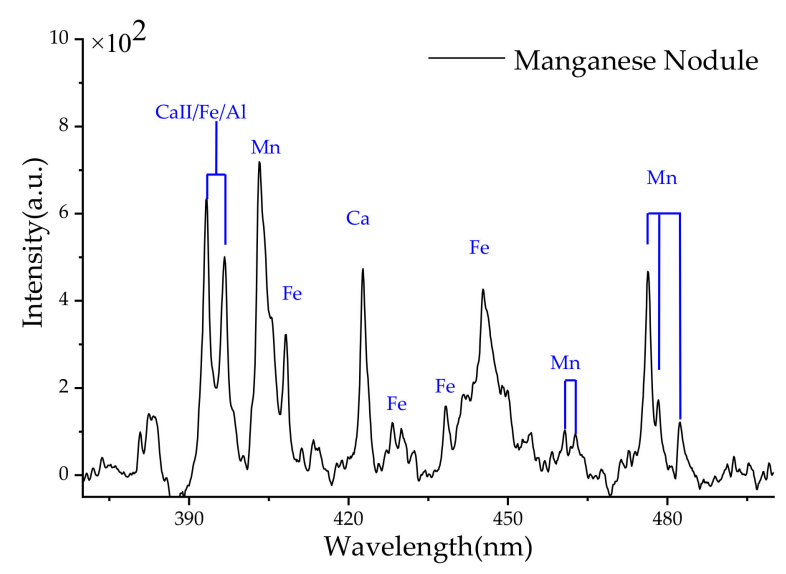

Figure 5. Typical spectra of a manganese nodule sample from deep sea in Jiaozhou Bay.

In order to verify the feasibility of LIBSea II for quantitative analysis of submerged solids, field experiments were also carried out in Jiaozhou Bay by using the $\mathrm{Zn}-\mathrm{Cu}$ alloy samples with four different $\mathrm{Zn} / \mathrm{Cu}$ mass ratios and two pure metal samples. The concentrations of $\mathrm{Zn}$ and $\mathrm{Cu}$ are ranging from 4.97\% to 99.99\% (S1: Zn 4.97\% and Cu95.03\%, S2: Zn 50.15\% and Cu 49.85\%, S3: Zn 80.01\% and Cu 19.99\%, S4: Zn 95.03\% and Cu 4.97\%, S5: Zn 99.99\%, S6: Cu 99.99\%). The samples were fixed on a one-dimensional linear rotating stage to avoid continuous breakdown in one site on the sample surface. 
Each spectrum was recorded with a delay time of $400 \mathrm{~ns}$ and an exposure time of $1 \mathrm{~ms}$, and 20 replicate spectra were acquired for each sample. The original spectral data were pre-processed by background subtraction and then normalized by the total intensity of the whole spectrum. For quantitative analysis, multiple linear regression was used to build the calibration model in order to reduce the matrix effect and the instability of LIBS signals. The concentration of the element to be measured in the multiple linear regression model is expressed as $Y=b_{0}+\sum_{i=1}^{n} a_{i} X_{i}+\varepsilon_{i}$, where $Y$ is the concentration of the element, $X_{i}$ is the intensity of the selected analyte lines, $\varepsilon_{i}$ is the error term, $a_{i}$ is the regression coefficient of multiple linear regression and $b_{0}$ is the linear regression constant. The intensities of three $\mathrm{Zn}$ lines (Zn I 468 nm, Zn I 472 nm, Zn I 481 nm) and three Cu lines (Cu I 510 nm, Cu I 515 nm, Cu I 521 nm) were selected as the input variables for the multiple linear regression model. The correlation relationships between the predicted concentration and reference concentration of $\mathrm{Zn}$ and $\mathrm{Cu}$ are shown in Figure 6. We can see a relatively high linearity of the calibration curve with the correlation coefficients $\left(R^{2}\right)$ of 0.989 and 0.979 for $\mathrm{Zn}$ and $\mathrm{Cu}$, respectively. These results indicate that LIBSea II for in-situ direct detection and quantitative analysis of submerged solids in real seawater environment. More works are still needed to test the analytical performance of the system, as well as the influence of oceanic environments on in-situ quantitative analysis of submerged solid targets.
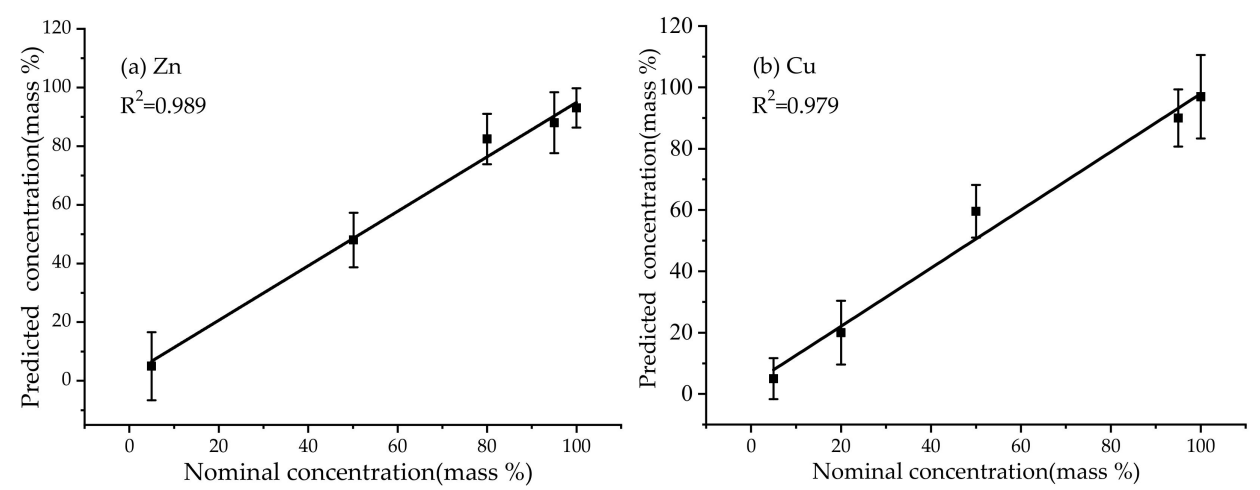

Figure 6. The correlation relationship between predicted concentration and nominal concentration of $\mathrm{Zn}(\mathbf{a})$ and $\mathrm{Cu}(\mathbf{b})$ based on multiple linear regression.

\subsection{Preliminary Results in sea Trials}

A deep-sea trial was carried out at the Haima cold seep area of the South China Sea in May 2019. The main purpose of the trial is to verify that in-situ experiments can be performed in deep sea.Figure 7a shows the picture of LIBSea II system deployed on the Haima ROV. During the sea trial, as ROV rising to sea surface and dived to seafloor, we obtained a large number of depth profiles data which were not shown, since it was not the focus of this paper. A carbonate rock sample, which was typical in cold seep area, was used for deep-sea LIBS detection. The spectrum of the carbonate rock sample was successfully obtained at the depth of $1400 \mathrm{~m}$, as shown in Figure $7 \mathrm{~b}$. From the spectrum in Figure 7b, we can see clearly the atomic line of Ca I $422 \mathrm{~nm}$, Na I 588/589 nm, and K I $766 / 769 \mathrm{~nm}$. It is worth noting that the strong molecular bands of calcium hydroxide are also detectable on either side of the Na I 588/589 nm line. The band around $554 \mathrm{~nm}$ is assigned to the green system $\mathrm{B}^{2} \Sigma^{+}-\mathrm{X}^{2} \Sigma^{+}$of the triatomic radical $\mathrm{CaOH}$, while the band around $623 \mathrm{~nm}$ is assigned to the orange-red system $\mathrm{A}^{2} \Pi-\chi^{2} \Sigma^{+}$of $\mathrm{CaOH}[36,37]$. The previous research revealed that $\mathrm{CaOH}$ molecular emissions (homogeneous distribution, longer lifetime, and high emission intensity) can improve the analytical performances of underwater LIBS by using the $\mathrm{CaOH}$ molecular bands instead of Ca II and Ca I lines. And the quantification results of $\mathrm{CaOH}$ are excellent with higher stability, less self-absorption, and reduced matrix effect. The acquisition of $\mathrm{CaOH}$ molecular signal may provide a new approach for improving the performances of underwater LIBS analysis [38]. The results showed that the LIBSea II system was feasible in deep-sea submerged solid detection. In the future works, we plan to integrate an auto-focus module in LIBSea II system and develop the signal processing methods for qualitative 
analysis, aiming to enable LIBS technology to be practically applied for the in-situ exploration in deep-sea polymetallic areas.
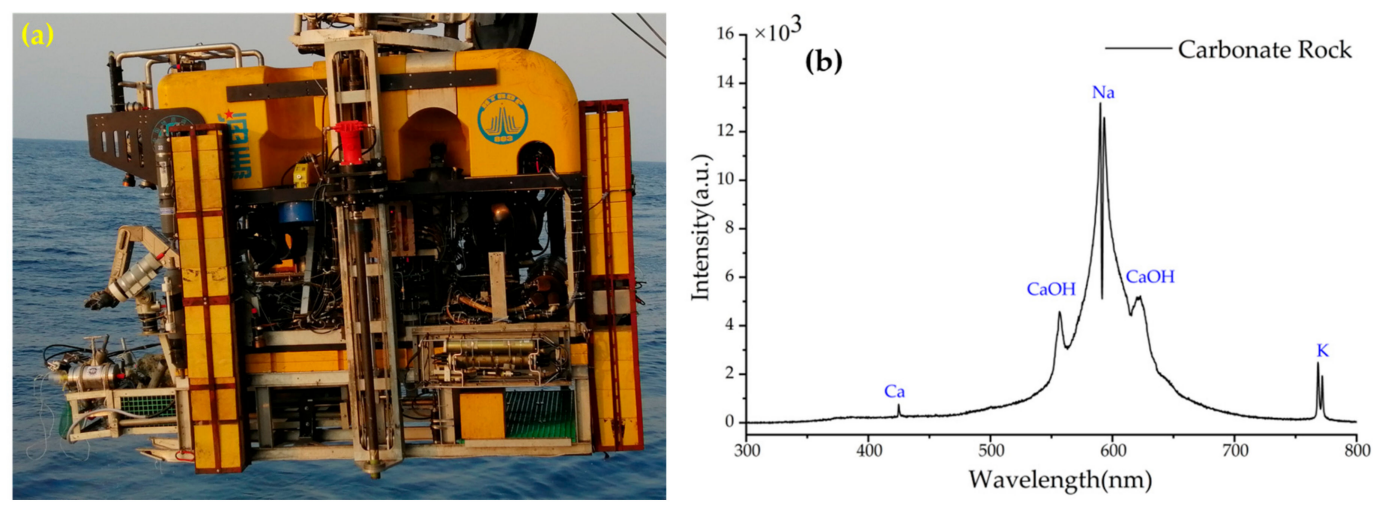

Figure 7. (a) LIBSea II mounted on the Haima ROV for in-situ experiments in the Haima cold seep area (b) Typical spectra of carbonate rock measured in deep sea.

\section{Conclusions}

In this work, a more compact and lighter underwater LIBS system named LIBSea II was developed for the in-situ detection of submerged solid samples. The system can be deployed with ROVs and is capable of performing in-situ, multi-element analysis of submerged solid at depths of up to $5000 \mathrm{~m}$. The system is encapsulated in a pressure housing with the size of $\Phi 190 \mathrm{~mm} \times \mathrm{L} 588 \mathrm{~mm}$. The system consists of a Nd:YAG laser at $1064 \mathrm{~nm}$, an optical spectrometer, optical layout, a power supply module and an internal environment sensor. The laser energy of $6 \mathrm{~mJ}$ and delay time of $400 \mathrm{~ns}$ were firstly determined by optimizing the system experimental parameters in the laboratory. Field tests of the system in shallow sea were then performed with various pure metal, alloy samples and manganese nodule samples from deep sea to show the detection performance of the LIBSea II system. There was a good consistency between the spectra measured in shallow sea and in laboratory, and the feasibility of LIBSea II for direct detection and quantitative analysis of submerged solids were also demonstrated. The deep-sea trial was carried out in the South China Sea in May 2019 by deploying on the Haima ROV to verify that the system can be operated in deep sea. The atomic lines of $\mathrm{K}, \mathrm{Na}, \mathrm{Ca}$ and strong molecular bands of $\mathrm{CaOH}$ from a carbonate rock sample were obtained for the first time at the depth of $1400 \mathrm{~m}$, which proved the feasibility of LIBSea II in deep-sea environment. Our future work will focus on how to apply this equipment to in-situ quantitative and qualitative analysis of submerged sediments and rocks. We plan to place the system on a high-precision motor and use ROV's manipulator for precise focusing of the system. In addition, the adoption of more advanced data processing methods will be helpful in in-situ quantitative and qualitative analysis of submerged sediments and rocks. Furthermore, the combination of extensive laboratory data and sea-trials data to establish the correction model between LIBS signals and environment factors seems particularly important. It is hoped that the underwater LIBS system through optimization and upgrading can make important contributions to the deep-sea explorations.

Author Contributions: J.G. and R.Z. initiated and supervised the research project. C.L., J.G. proposed the idea. J.G., C.L. and K.C. developed the prototype. C.L., J.G. and Y.T. conceived and designed the experiments. C.L., C.Z. and W.Y. performed the experiments. C.L. processed the data and wrote the initial draft. The final revisions and writing were done by Y.T. All authors have read and agreed to the published version of the manuscript.

Funding: National Key Research and Development Program of China (2016YFC0302102), Provincial Key Research and Development Program of Shandong, China (2019JZZY010417, 2019GHZ010), Fundamental Research Funds for the Central Universities (201822003).

Conflicts of Interest: The authors declare no conflict of interest. 


\section{References}

1. Blair, T.; Tomoko, T.; Takumi, S.; Tetsuo, S.; Ayaka, T.; Ayumu, M.; Tatsuo, N.; Toshihiko, O.; Ohki, K. Development of a deep-sea laser-induced breakdown spectrometer for in situ multi-element chemical analysis. Deep Sea Res. Part I Oceanogr. Res. Pap. 2015, 95, 20-36.

2. Wang, Z.; Dong, F.; Zhou, W. A rising force for the world-wide development of laser-induced breakdown spectroscopy. Plasma Sci. Technol. 2015, 17, 617-620. [CrossRef]

3. Vogel, A.; Venugopalan, V. Mechanisms of pulsed laser ablation of biological tissues. Chem. Rev. 2003, 103, 577-644. [CrossRef]

4. Zhang, D.; Gökce, B.; Barcikowski, S. Laser synthesis and processing of colloids: Fundamentals and applications. Chem. Rev. 2017, 117, 3990-4103. [CrossRef]

5. Choo, K.L.; Ogawa, Y.; Kanbargi, G.; Otra, V.; Raff, L.M.; Komanduri, R. Micromachining of silicon by short-pulse laser ablation in air and under water. Mater. Sci. Eng. A 2004, 372, 145-162. [CrossRef]

6. Lee, T.; Luo, W.; Li, Q.; Demirci, H.; Guo, L.J. Laser-Induced Focused Ultrasound for Cavitation Treatment: Toward High-Precision Invisible Sonic Scalpel. Small 2017, 13, 1701555. [CrossRef] [PubMed]

7. Meslin, P.Y.; Gasnault, O.; Forni, O.; Schröder, S.; Cousin, A.; Berger, G.; Clegg, S.M.; Lasue, J.; Maurice, S.; Sautter, V.; et al. Soil diversity and hydration as observed by ChemCam at Gale Crater, Mars. Science 2013, 341, 6153. [CrossRef] [PubMed]

8. Nachon, M.; Clegg, S.M.; Mangold, N.; Schröder, S.; Kah, L.C.; Dromart, G.; Ollila, A.; Johnson, J.R.; Oehler, D.Z.; Bridges, J.C.; et al. Calcium sulfate veins characterized by ChemCam/Curiosity at Gale crater, Mars. J. Geophys. Res. Planets 2014, 119, 1991-2016. [CrossRef]

9. Maurice, S.; Clegg, S.M.; Wiens, R.C.; Gasnault, O.; Rapin, W.; Forni, O.; Cousin, A.; Sautter, V.; Mangold, N.; le Deit, L.; et al. ChemCam activities and discoveries during the nominal mission of the Mars Science Laboratory in Gale crater, Mars. J. Anal. Atomic Spectrom. 2016, 31, 863-889. [CrossRef]

10. Kennedy, P.K.; Hammer, D.X.; Rockwell, B.A. Laser-induced breakdown in aqueous media. Progress Quantum Electr. 1997, 21, 155-248. [CrossRef]

11. de Giacomo, A.; Dell'Aglio, M.; de Pascale, O. Single pulse-laser induced breakdown spectroscopy in aqueous solution. Appl. Phys. A 2004, 79, 1035-1038. [CrossRef]

12. de Giacomo, A.; Dell'Aglio, M.; Colao, F.; Fantoni, R.; Lazic, V. Double-pulse LIBS in bulk water and on submerged bronze samples. Appl. Surf. Sci. 2005, 247, 157-162. [CrossRef]

13. Sakka, T.; Oguchi, H.; Masai, S.; Hirata, K.; Ogata, Y.H.; Saeki, M.; Ohba, H. Use of a long-duration ns pulse for efficient emission of spectral lines from the laser ablation plume in water. Appl. Phys. Lett. 2006, 88, 061120. [CrossRef]

14. Tian, Y.; Xue, B.; Song, J.; Lu, Y.; Zheng, R. Non-gated laser-induced breakdown spectroscopy in bulk water by position-selective detection. Appl. Phys. Lett. 2015, 107, 111107. [CrossRef]

15. Hou, H.; Tian, Y.; Li, Y.; Zheng, R. Study of pressure effects on laser induced plasma in bulk seawater. J. Anal. At. Spectrom. 2014, 29, 169-175. [CrossRef]

16. Hou, H.; Li, Y.; Tian, Y.; Yu, Z.; Zheng, R. Plasma condensation effect by ambient pressure in laser induced breakdown spectroscopy. Appl. Phys. Express 2014, 7, 032402. [CrossRef]

17. Tian, Y.; Li, Y.; Wang, L.; Huang, F.; Lu, Y.; Guo, J.; Zheng, R. Laser-induced plasma in water at high pressures up to 40 MPa: A time-resolved study. Opt. Express 2020, 28, 18122-18130. [CrossRef]

18. Wang, L.; Tian, Y.; Li, Y.; Lu, Y.; Guo, J.; Ye, W.; Zheng, R. Spectral characteristics of underwater laser-induced breakdown spectroscopy under high-pressure conditions. Plasma Sci. Technol. 2020, 22, 074004. [CrossRef]

19. Jabbar, A.; Hou, Z.; Liu, J.; Ahmed, R.; Mahmood, S.; Wang, Z. Calibration-free analysis of immersed metal alloys using long-pulse-duration laser-induced breakdown spectroscopy. Spectrochim. Acta Part B At. Spectrosc. 2019, 157, 84-90. [CrossRef]

20. Li, Q.; Tian, Y.; Xue, B.; Li, N.; Ye, W.; Lu, Y.; Zheng, R. Improvement in the analytical performance of underwater LIBS signals by exploiting the plasma image information. J. Anal. At. Spectrom. 2020, 35, 366-376. [CrossRef]

21. Guirado, S.; Fortes, F.J.; Lazic, V.; Laserna, J.J. Chemical analysis of archeological materials in submarine environments using laser-induced breakdown spectroscopy. On-site trials in the Mediterranean Sea. Spectrochim. Acta Part B At. Spectrosc. 2012, 74, 137-143. [CrossRef] 
22. Guirado, S.; Fortes, F.J.; Laserna, J.J. Elemental analysis of materials in an underwater archeological shipwreck using a novel remote laser-induced breakdown spectroscopy system. Talanta 2015, 137, 182-188. [CrossRef]

23. Thornton, B.; Masamura, T.; Takahashi, T.; Ura, T.; Ohki, K.; Sakka, T. Development and field testing of laser-induced breakdown spectroscopy for in situ multi-element analysis at sea. In Proceedings of the 2012 Oceans, Salt Lake City, UT, USA, 20-24 February 2012; pp. 1-6.

24. Thornton, B.; Sakka, T.; Takahashi, T.; Tamura, A.; Matsumoto, A.; Ura, T. Laser-induced breakdown spectroscopy for in situ chemical analysis at sea. In Proceedings of the 2013 IEEE International Underwater Technology Symposium, Tokyo, Japan, 5-8 March 2013; pp. 1-7.

25. Takahashi, T.; Yoshino, S.; Takaya, Y.; Nozaki, T.; Ohki, K.; Ohki, T.; Sakka, T.; Blair, T. Quantitative in situ mapping of elements in deep-sea hydrothermal vents using laser-induced breakdown spectroscopy and multivariate analysis. Deep Sea Res. Part I Oceanogr. Res. Pap. 2020, 103232. [CrossRef]

26. Guo, J.; Lu, Y.; Cheng, K.; Song, J.; Ye, W.; Li, N.; Zheng, R. Development of a compact underwater laser-induced breakdown spectroscopy (LIBS) system and preliminary results in sea trials. Appl. Opt. 2017, 56, 8196-8200. [CrossRef] [PubMed]

27. Ye, W.; Guo, J.; Li, N.; Qi, F.; Cheng, K.; Zheng, R. Depth Profiling Investigation of Seawater Using Combined Multi-Optical Spectrometry. Appl. Spectrosc. 2020, 74, 563-570. [CrossRef] [PubMed]

28. Tian, Y.; Xue, B.; Song, J.; Lu, Y.; Li, Y.; Zheng, R. Comparative investigation of laser-induced breakdown spectroscopy in bulk water using 532-and 1064-nm lasers. Appl. Phys. Express 2017, 10, 072401. [CrossRef]

29. Tian, Y.; Wang, L.; Xue, B.; Chen, Q.; Li, Y. Laser focusing geometry effects on laser-induced plasma and laser-induced breakdown spectroscopy in bulk water. J. Anal. At. Spectrom. 2019, 34, 118-126. [CrossRef]

30. Tian, Y.; Xue, B.; Song, J.; Lu, Y.; Zheng, R. Stabilization of laser-induced plasma in bulk water using large focusing angle. Appl. Phys. Lett. 2016, 109, 061104.1-061104.5. [CrossRef]

31. Song, J.; Guo, J.; Tian, Y.; Xue, B.; Lu, Y.; Zheng, R. Investigation of laser-induced plasma characteristics in bulk water under different focusing arrangements. Appl. Opt. 2018, 57, 1640-1644. [CrossRef]

32. Baek, S.J.; Park, A.; Ahn, Y.J.; Choo, J. Baseline correction using asymmetrically reweighted penalized least squares smoothing. Analyst 2015, 140, 250-257. [CrossRef]

33. Lam, J.; Amans, D.; Chaput, F.; Diouf, M.; Ledoux, G.; Mary, N.; Masenelli-Varlot, K.; Motto-Ros, V.; Dujardin, C. $\gamma-\mathrm{Al}_{2} \mathrm{O}_{3}$ nanoparticles synthesised by pulsed laser ablation in liquids: A plasma analysis. Phys. Chem. Chem. Phys. 2014, 16, 963-973. [CrossRef] [PubMed]

34. Li, N.; Guo, J.; Zhu, L.; Lu, Y.; Tian, Y.; Zheng, R. Effects of Ambient Temperature on Laser-Induced Plasma in Bulk Water. Appl. Spectrosc. 2019, 73, 1277-1283. [CrossRef] [PubMed]

35. Li, N.; Guo, J.; Zhang, C.; Zhang, Y.; Li, Q.; Tian, Y.; Zheng, R. Salinity effects on elemental analysis in bulk water by laser-induced breakdown spectroscopy. Appl. Opt. 2019, 58, 3886-3891. [CrossRef]

36. Pearse, R.W.B.; Gaydon, A.G. Identification of Molecular Spectra; Chapman and Hall: London, UK, 1976.

37. Gaydon, A.G. Green and orange band spectra of $\mathrm{CaOH}, \mathrm{CaOD}$ and calcium oxide. Proc. R. Soc. Lond. Ser. A Math. Phys. Sci. 1955, 231, 437-445.

38. Tian, Y.; Hou, S.; Wang, L.; Duan, X.; Xue, B.; Lu, Y.; Guo, J.; Li, Y. CaOH Molecular Emissions in Underwater Laser-Induced Breakdown Spectroscopy: Spatial-Temporal Characteristics and Analytical Performances. Anal. Chem. 2019, 91, 13970-13977. [CrossRef] [PubMed]

Publisher's Note: MDPI stays neutral with regard to jurisdictional claims in published maps and institutional affiliations.

(C) 2020 by the authors. Licensee MDPI, Basel, Switzerland. This article is an open access article distributed under the terms and conditions of the Creative Commons Attribution (CC BY) license (http://creativecommons.org/licenses/by/4.0/). 